\title{
Prevalence of Vitamin D Deficiency in Patients Presenting with an Orthopaedic Trauma at a Tertiary Centre in South India - Implications and Protocols for Replacement Therapy
}

\author{
Cherian VM, MS Ortho, Gouse M, MS Orth, Albert S, MS Orth, Jayasankar V, MS Orth \\ Department of Orthopaedics, Christian Medical College, Vellore, India
}

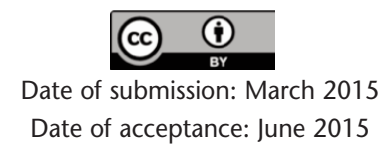

\section{INTRODUCTION}

Vitamin D has been the focus of much scientific literature in recent years owing to various studies showing its association with a wide variety of pathological conditions ${ }^{1,2}$. Sun exposure, diet and fortified supplementation account for a bulk of Vitamin D intake in humans. Activation of vitamin D is sequential and requires sun exposure for conversion of 7dehydrocholesterol to Vitamin D3. Further metabolism in the liver converts Vitamin D3 to 25 -hydroxyvitamin D3. Conversion to its active form 1,25 dihydroxyvitamin D3 (Calcitriol) occurs in the kidneys ${ }^{2}$. The importance of Vitamin D in calcium metabolism and bone health is well known and documented. Controversies exist regarding the true prevalence of hypovitaminosis, however in developing countries the prevalence of vitamin D deficiency in all age groups is probably higher ${ }^{3}$. Adding to this the burden and morbidity of skeletal trauma, persistent deficiency may have a deleterious effect in the injured ${ }^{4,5}$. Vitamin D, with its positive effect on bone health does play a role in the biology of fracture repair and remodelling ${ }^{6}$. The role of Vitamin D replacement as sole biological effectors in fracture repair may be difficult to quantify and confounded by other variables at play in bone healing. Studies looking at vitamin $\mathrm{D}$ levels in orthopaedic patients have also shown significant levels of deficiency and have put forward recommendations for evaluation and supplementation ${ }^{7,8}$.

Many studies in the last decade have associated Vitamin D with various diseases with varied results on their outcome ${ }^{1,9,5}$. It has been implicated in cancer biology, diabetes, hypertension, multiple sclerosis, slipped capital femoral epiphysis and even falls in the elderly to name a few ${ }^{10,11,12,13}$.

In western countries, fortified food products are a major source of Vitamin D ${ }^{9}$. Policies on food fortification with
Vitamin D are yet to be established in many developing countries and the true prevalence of deficiency is not known. Few studies in select population groups and cohorts seem to reflect that prevalence in India is much higher than what would be expected ${ }^{14,13}$. We sought to determine the prevalence of Hypo-vitaminosis D in patients who presented with an orthopaedic injury and suggest a cost effective protocol if required for supplementation and follow up.

\section{MATERIALS AND METHODS}

This study was approved by the Instuitional Review Board (IRB Min .No 8393 dated 31.07.2013). We checked the Vitamin D levels of all patients who presented to the Accident and Emergency/ Orthopaedic Department Unit-1 with fractures from August 2013 to December 2013 Vellore. Christian Medical College (CMC) Vellore is a tertiary trauma care centre located in South India. We included patients in the age group 25 to 70 years who presented immediately following an orthopaedic injury the accident and emergency department. We excluded patients who presented after treatment at another centre, patients who were on prior supplementation of vitamin D and patients who presented with sepsis/ septic shock. We chose to exclude elderly patients as many would have been on supplements and their exposure to sunlight would have been considerably reduced. Patients who met our inclusion criteria, had along with other appropriate investigations, 25 hydroxyvitamin D3 levels were checked on collected samples using a Electro chemiluminescence immune assay system (Roche E- 170 modular system) in our in hospital clinical Biochemistry laboratory. Samples were obtained within a few hours of the injury prior to any administration of anaesthesia or any surgical procedure. Reviewing existing literature and recommendations we chose to classify our 
Table I: Percentage of Vitamin D deficiency among male and female patients

\begin{tabular}{|lccccccc|}
\hline SEX & Number & Percentage & $\begin{array}{c}\text { Less than } \\
\text { 10ng/dl }\end{array}$ & $\mathbf{1 0 - 2 0 n g / d l}$ & $\mathbf{2 1 - 3 2 n g / d l}$ & $\begin{array}{c}\text { More than } \\
\text { 32ng/dl }\end{array}$ & P- value \\
\hline Male & 122 & $76.3 \%$ & $46(37.7 \%)$ & $50(41 \%)$ & $19(15.6 \%)$ & $7(5.7 \%)$ & 0.378 \\
Female & 38 & 23.7 & $19(50 \%)$ & $15(39.5 \%)$ & $3(7.9 \%)$ & $1(2.6 \%)$ & \\
\hline
\end{tabular}

Table II: Prevalence of Vitamin D among patients with closed and open fractures

\begin{tabular}{|c|c|c|c|c|c|c|c|}
\hline $\begin{array}{l}\text { Injury-open/ } \\
\text { closed fractures }\end{array}$ & Number & percentage & $\begin{array}{l}\text { Less than } \\
10 \mathrm{ng} / \mathrm{dl} .\end{array}$ & $10-20 \mathrm{ng} / \mathrm{dl}$ & $21-32 \mathrm{ng} / \mathrm{dl}$ & $\begin{array}{c}\text { More } \\
\text { than 32ng/dl }\end{array}$ & $P$ value \\
\hline Open & 50 & 31.3 & $18(36 \%)$ & $19(38 \%)$ & $10(20 \%)$ & $3(6 \%)$ & 0.458 \\
\hline Closed & 110 & 68.8 & $47(42.7 \%)$ & $46(41.8 \%)$ & $12(10.9 \%)$ & $5(4.5 \%)$ & \\
\hline
\end{tabular}

Table III: Vitamin D levels among patients with various injury patterns

\begin{tabular}{|c|c|c|c|c|c|}
\hline Injury patterns & Number(percentage) & $\begin{array}{l}\text { Less than } \\
10 \mathrm{ng} / \mathrm{dl} .\end{array}$ & $10-20 \mathrm{ng} / \mathrm{dl}$ & $21-32 \mathrm{ng} / \mathrm{dl}$ & $\begin{array}{c}\text { More than } \\
32 \mathrm{ng} / \mathrm{dl}\end{array}$ \\
\hline Pelvis/Acetab & $4(2.5 \%)$ & 1 & 2 & 1 & 0 \\
\hline Hip & $26(16.3 \%)$ & 10 & 12 & 4 & 0 \\
\hline Femur & $14(8.8 \%)$ & 3 & 6 & 3 & 2 \\
\hline Knee & $8(5 \%)$ & 2 & 5 & 1 & 0 \\
\hline Patella & $1(0.6 \%)$ & 1 & 0 & 0 & 0 \\
\hline Ankle & $2(1.2 \%)$ & 1 & 0 & 1 & 0 \\
\hline Tibia & $16(10 \%)$ & 4 & 7 & 3 & 2 \\
\hline Foot & $18(11.3 \%)$ & 5 & 8 & 3 & 2 \\
\hline Shoulder & $3(1.9 \%)$ & 1 & 0 & 2 & 0 \\
\hline Clavicle & $3(1.9 \%)$ & 1 & 2 & 0 & 0 \\
\hline Humerus & $14(8.8 \%)$ & 9 & 5 & 0 & 0 \\
\hline Elbow & $1(0.6 \%)$ & 0 & 0 & 0 & 1 \\
\hline Forearm & $11(6.9 \%)$ & 5 & 5 & 1 & 0 \\
\hline Wrist & $13(8.1 \%)$ & 6 & 5 & 1 & 0 \\
\hline Multiple injuries & $26(16.3 \%)$ & 16 & 8 & 2 & 0 \\
\hline Total & 160 & 65 & 65 & 22 & 8 \\
\hline
\end{tabular}

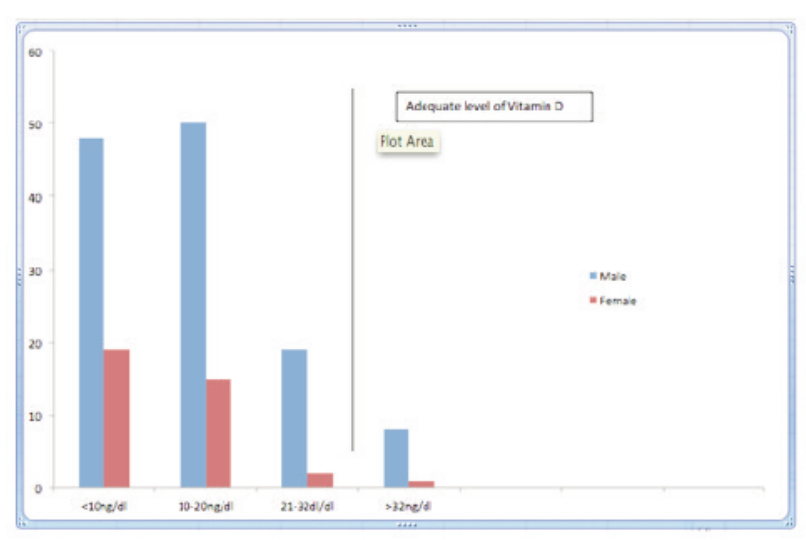

patients as follows ${ }^{7}$ severely deficient $<10 \mathrm{ng} / \mathrm{mL}$, Moderately deficient 11-20ng/mL, Insufficient 21-32ng/mL, Adequate/ Normal $\geq 32 \mathrm{ng} / \mathrm{mL}$. Those patients who are deficient were supplemented with vitamin D granules once a week for six to eight weeks.

\section{STATISTICAL ANALYSIS}

The required sample size to find the prevalence of low Vitamin D among trauma patients was found to be 160 subjects with $7.5 \%$ precision, $95 \%$ confidence limits.

Descriptive statistics such as frequency and percentages were calculated for categorical variables. Summary measure such as mean /median with standard deviation / interquartile range was calculated for continuous variables. Vitamin $d$ levels were associated with demographic variables using chi square test. $\mathrm{P}$ value less than 0.05 was considered to be statistics significant. Patient demographic data and the nature of orthopaedic injury sustained were also documented. Data was collected in a clinical research form, entered in Epidata V 3.1 and statistical analysis was performed using SPSS software version 17 (SPSS, Inc., Chicago, Illinois).

\section{RESULTS}

The average age of the patients in our population was 42.51(25-70 years). Patient demographic details are 
presented in Table I. All patients were from the same geographical region and presented within a few hours from the injury. The majority of the patients belong to a productive earning segment of the community and none of the patients were on prior calcium or Vitamin supplements.

More male patients presented following injury, a representative sample of our injured population. Moreover being a tertiary centre, a significant number of our patients had open fractures.

Overall only 8 of 160 patients (5\%) had adequate vitamin D levels (>32ng/dl). Breakdown of injury versus Vitamin D levels are given in Table III. It can be observed that prevalence of hypo-vitaminosis is uniformly distributed with the overall prevalence being $82 \%$ with the cut-off set at $20 \mathrm{ng} / \mathrm{dl}$ and increasing to $95 \%$ when shifted to $32 \mathrm{ng} / \mathrm{dl}$. Fig 1 .

\section{DISCUSSION}

In south Indian weather is predominantly warm through the year and the population being universally dark skinned. The seasons through the year on the South Indian plains are once famously described as being "hot, hotter and hottest" through the year. Individual sun exposure is unlikely to be reduced during any part of the year. Despite controversies existing regarding the normal acceptable vitamin D level, various studies in otherwise asymptomatic cohorts world over have shown alarmingly low levels of Vitamin D 1,3,15,16. What constitutes hypovitaminosis is also confusing with different studies using different cut off values to define deficiency. The cause of deficiency may be multi factorial ranging from absence fortification to ineffective sun exposure. The prevalence is bound to increase when the cut off for deficiency is lowered. What constitutes a normal level in a south Indian population has not been established. Most studies use levels recommended by either the Institute of Medicine $(>20 \mathrm{ng} / \mathrm{dl})$ or the International osteoporosis foundation $(>30 \mathrm{ng} / \mathrm{dl})^{17,18}$.

In our series the majority of the trauma patient was deficient of vitamin D (82\%). We compared our result with other studies done in south India in various study population. The percentage of vitamin D deficiency among all studies was identical $^{19-22}$.

The patients in this group may be considered to represent a productive cross section of the community considering the average age. None of the patients had been tested or treated for Vitamin D deficiency prior to their admission at our institution. Vitamin D deficiency in the adult patient need not always be associated with frank radiological signs of osteomalacia. Other signs and symptoms like vague bone pains and proximal muscle weakness are not always evaluated or treated and hence patients may be labelled as clinically normal ${ }^{23,24}$. Even if patients in this group were clinically asymptomatic, they may all benefit from supplementation post injury considering the benefit of Vitamin D on bone health, calcium metabolism and improved rehabilitative potential ${ }^{24,25}$. In our series all patient who had vitamin D deficient were supplements with calcirol granules sachet as recommended .M Brinker et at evaluated patients with an unexplained non-union and found that a majority of patients $(84 \%)$ had a metabolic bone disorder, the commonest being Vitamin D deficiency and union occurred in some patients with just medical treatment ${ }^{26}$.

However the precise benefit of Vitamin D supplementation in every patient who have had skeletal injury in terms of infection control, prevention of non union and improved rehabilitation are difficult to assess ${ }^{6,26,27}$. However supplementation in this group would be beneficial in the absence of standardised food fortification programs. Dark skinned individuals are also at a slight disadvantage as the metabolism of vitamin D to its active form is reduced ${ }^{2}$.

The effect of Vitamin D on muscle power and function in a dose/level dependent manner is well known and replacement therapy in rehabilitative phase post trauma or surgery might be especially beneficial ${ }^{2,28}$. In patients planned to undergo Total hip replacement Functional scores were significantly lower in patients with low Vitamin D levels and showed improvement with replacement therapy ${ }^{29}$.

Hypervitaminosis with replacement therapy is a rare event and often described in literature as a result of accidental ingestion or a dispensing error. The upper safe limit of Vitamin D has not been established and upto 10,000 units per day may be safe ${ }^{2,30}$. The IOM (Institute of Medicine) has set 4,000 units as a recommended daily intake level. Treatment protocols using 60,000 units once a week for six to eight weeks is unlikely to induce hypervitaminosis in patients who have received no prior therapy ${ }^{17}$.

\section{CONCLUSION}

In this series the overall prevalence of Vitamin D deficiency is $95 \%$ which is abnormally high. Routine evaluation of Vitamin D in trauma patients may not be required in these trauma patients. Regular supplement of vitamin D therapy provided a favourable outcome in the trauma patients. Other modalities of Vitamin D supplementation such as, sun exposure and diet modification with fortification in this patient group in the recovery/ rehabilitative period post injury is of considerable importance.

\section{ACKNOWLEDGEMENT}

Our heart full gratitude to Dr. Visalakshi, department of biostatistics, for her kind help for analysis of the data. 


\section{REFERENCES}

1. Mithal A, Wahl DA, Bonjour J-P, Burckhardt P, Dawson-Hughes B, Eisman JA, et al. Global vitamin D status and determinants of hypovitaminosis D. Osteoporos Int J Establ Result Coop Eur Found Osteoporos Natl Osteoporos Found USA. 2009 Nov; 20(11): 1807-20.

2. Holick MF. Vitamin D Deficiency. N Engl J Med. 2007; 357(3): 266-81.

3. Suresh Kumar R, Syed S, Anand Kumar A, Subha Kumari KN, Sajitha K. Serum vitamin d levels in Indian patients with multiple sclerosis. Indian J Clin Biochem IJCB. 2013 Jul; 28(3): 255-8.

4. Burckhardt P. Calcium and Vitamin D in the treatment and prevention of osteoporosis: the actual dilemma. Ther Umsch Rev Thérapeutique. 2012 Mar; 69(3): 153-61.

5. Spedding S, Vanlint S, Morris H, Scragg R. Does vitamin d sufficiency equate to a single serum 25-hydroxyvitamin d level or are different levels required for non-skeletal diseases? Nutrients. 2013; 5(12): 5127-39.

6. Briggs AD, Kuan V, Greiller CL, Maclaughlin BD, Ramachandran M, Harris T, et al. Longitudinal study of vitamin D metabolites after long bone fracture. J Bone Miner Res Off J Am Soc Bone Miner Res. 2013 Jun; 28(6): 1301-7.

7. Bee C, Sheerin DV, Wuest TK, Fitzpatrick DC, Fitzpatrick DC. Serum Vitamin D Levels in Orthopaedic Trauma Patients Living in the Northwestern United States. J Orthop Trauma [Internet]. 2012 [cited 2013 Jun 21]; Available from: http://pdfs.journals.lww.com/jorthotrauma/9000/00000/Serum_Vitamin_D_Levels_in_Orthopaedic_Trauma.99687.pdf

8. Van den Bergh J, van Geel T, Geusens P. Should the vitamin D level be determined for all fracture patients? Ned Tijdschr Geneeskd. 2010; 154: A1758.

9. Yetley EA. Assessing the vitamin D status of the US population. Am J Clin Nutr. 2008 Aug; 88(2): 558S-564S.

10. Piziak VK, Rajab MH. An effective team approach to improve postoperative hip fracture care. J Orthop Trauma. 2011; 25(2): $72-5$.

11. Snellman G, Byberg L, Lemming EW, Melhus H, Gedeborg R, Mallmin H, et al. Long-term dietary vitamin D intake and risk of fracture and osteoporosis: a longitudinal cohort study of Swedish middle-aged and elderly women. J Clin Endocrinol Metab. 2013 Dec 10; jc20131738.

12. Basit S. Vitamin D in health and disease: a literature review. Br J Biomed Sci. 2013; 70(4): 161-72.

13. Madhuri V, Arora SK, Dutt V. Slipped capital femoral epiphysis associated with vitamin D deficiency: a series of 15 cases. Bone Jt J. 2013 Jun; 95-B(6): 851-4.

14. Beloyartseva M, Mithal A, Kaur P, Kalra S, Baruah MP, Mukhopadhyay S, et al. Widespread vitamin D deficiency among Indian health care professionals. Arch Osteoporos. 2012 Dec; 7(1-2): 187-92.

15. Taneja MK, Taneja V. Vitamin d deficiency in e.N.T. Patients. Indian J Otolaryngol Head Neck Surg Off Publ Assoc Otolaryngol India. 2013 Jan; 65(1): 57-60.

16. Bogunovic L. Hypovitaminosis D in Patients Scheduled to Undergo Orthopaedic Surgery. A Single-Center Analysis. $J$ Bone $J t$ Surg Am. 2010 Oct 6; 92(13): 2300.

17. Institute of Medicine (US) Committee to Review Dietary Reference Intakes for Vitamin D and Calcium. Dietary Reference Intakes for Calcium and Vitamin D [Internet]. Ross AC, Taylor CL, Yaktine AL, Del Valle HB, editors. Washington (DC): National Academies Press (US); 2011 [cited 2014 Jan 21]. Available from: http:/www.ncbi.nlm.nih.gov/books/NBK56070/

18. Dawson-Hughes B, Mithal A, Bonjour J-P, Boonen S, Burckhardt P, Fuleihan GE-H, et al. IOF position statement: vitamin D recommendations for older adults. Osteoporos Int. 2010 Apr 27;21(7):1151-4.

19. Paul TV, Thomas N, Seshadri MS, Oommen R, Jose A, Mahendri NV. Prevalence of osteoporosis in ambulatory postmenopausal women from a semiurban region in Southern India: relationship to calcium nutrition and vitamin D status. Endocr Pract Off $J$ Am Coll Endocrinol Am Assoc Clin Endocrinol. 2008 Sep; 14(6): 665-71.

20. Londhey V. Vitamin D deficiency: Indian scenario. J Assoc Physicians India. 2011; 59(2011): 695-6.

21. Harinarayan CV. Prevalence of vitamin D insufficiency in postmenopausal south Indian women. Osteoporos Int J Establ Result Coop Eur Found Osteoporos Natl Osteoporos Found USA. 2005 Apr; 16(4): 397-402. 
22. Harinarayan CV, Ramalakshmi T, Prasad UV, Sudhakar D. Vitamin D status in Andhra Pradesh: a population based study. Indian J Med Res. 2008; 127(3): 211-8.

23. Sorbi R, Aghamirsalim MR. Knowledge of orthopaedic surgeons in managing patients with fragility fracture. Int Orthop. 2012 27; 36(6): 1275-9.

24. Reidenberg MM. Vitamin d and calcium supplementation to prevent fractures in adults. Ann Intern Med. 2013 17; $159(12)$ : 856.

25. Patton CM, Powell AP, Patel AA. Vitamin D in orthopaedics. J Am Acad Orthop Surg. 2012; 20(3): 123-9.

26. Brinker MR, O'Connor DP, Monla YT, Earthman TP. Metabolic and endocrine abnormalities in patients with nonunions. $J$ Orthop Trauma. 2007; 21(8): 557-70.

27. Van den Bergh J, van Geel T, Geusens P. Should the vitamin D level be determined for all fracture patients? Ned Tijdschr Geneeskd. 2010; 154: A1758.

28. Bischoff-Ferrari HA, Giovannucci E, Willett WC, Dietrich T, Dawson-Hughes B. Estimation of optimal serum concentrations of 25-hydroxyvitamin D for multiple health outcomes. Am J Clin Nutr. 2006; 84(1): 18-28.

29. Lavernia CJ, Villa JM, Iacobelli DA, Rossi MD. Vitamin D Insufficiency in Patients With THA: Prevalence and Effects on Outcome. Clin Orthop. 2014; 472(2): 681-6.

30. Jacobsen RB, Hronek BW, Schmidt GA, Schilling ML. Hypervitaminosis D Associated with a Vitamin D Dispensing Error. Ann Pharmacother. 2011 13; 45(10): e52-e52. 